\title{
Radar Evaluation of Optical Cloud Constraints to Space Launch Operations
}

\author{
Francis J. Merceret \\ NASA, John F. Kennedy Space Center, $\dot{F} L 32899$ \\ David A. Short ${ }^{\dagger}$ \\ ENSCO, Inc., Cocoa Beach, FL 32931 \\ Jennifer G. Ward ${ }^{\ddagger}$ \\ NASA, John F. Kennedy Space Center, FL 32899
}

\section{Introduction}

Weather constraints to launching space vehicles are designed to prevent loss of the vehicle or mission due to weather hazards (See, e.g., Ref 1). Constraints include Lightning Launch Commit Criteria (LLCC) designed to avoid natural and triggered lightning. The LLCC currently in use at most American launch sites including the Eastern Range and Kennedy Space Center require the Launch Weather Officer to determine the height of cloud bases and tops, the location of cloud edges, and cloud transparency. The preferred method of making these determinations is visual observation, but when that isn't possible due to darkness or obscured vision, it is permissible to use radar. $^{2}$

This note examines the relationship between visual and radar observations in three ways:

- A theoretical consideration of the relationship between radar reflectivity and optical transparency.

- An observational study relating radar reflectivity to cloud edge determined from in-situ measurements of cloud particle concentrations that determine the visible cloud edge.

- An observational study relating standard radar products to anvil cloud transparency.

It is shown that these three approaches yield results consistent with each other and with the radar threshold specified in Reference 2 for LLCC evaluation.

\footnotetext{
' Chief, Applied Meteorology Unit, NASA/YA-D, Kennedy Space Center, FL 32899, AIAA Membership applied for.

' Staff Scientist, ENSCO, Inc., 1980 N. Atlantic Ave, Ste 230, Cocoa Beach, FL 32931.

${ }^{\ddagger}$ Physical Scientist, NASA/YA-D, Kennedy Space Center, FL 32899.
} 


\section{Theoretical Relation of Reflectivity and Transparency}

The optical transparency of a cloud depends on the optical extinction coefficient (OEC) of the cloud and its geometric thickness. The cloud particles determine both the OEC and the radar reflectivity. Thus, there is a theoretical basis for a relationship between cloud optical transparency and radar reflectivity. Atlas et al. ${ }^{3}$ provides a theoretical approach for expressing the OEC of a cloud composed of ice crystals in terms of the radar reflectivity $\left(\mathrm{Z} \mathrm{mm}^{6} \mathrm{~m}^{-3}\right)$ and $\mathrm{D}_{0}$, the mass weighed average diameter of the cloud particles. The following equation is consistent with Figure 8 in Atlas et al. ${ }^{3}$

$$
\operatorname{OEC}\left(\mathrm{km}^{-1}\right)=196200^{*} \mathrm{Z} /\left(\mathrm{D}_{0}\right)^{1.8}
$$

where $D o$ is expressed in $\mu \mathrm{m}$. Figure 1 shows curves of the $O E C$ as a function of $D_{0}$ for three $d B Z$ $\left(\mathrm{dBZ}=10 \log _{10} Z\right)$ values: 5,0 , and -5 . The OEC increases with increasing $\mathrm{dBZ}$, but decreases with increasing $\mathrm{D}_{0}$. 


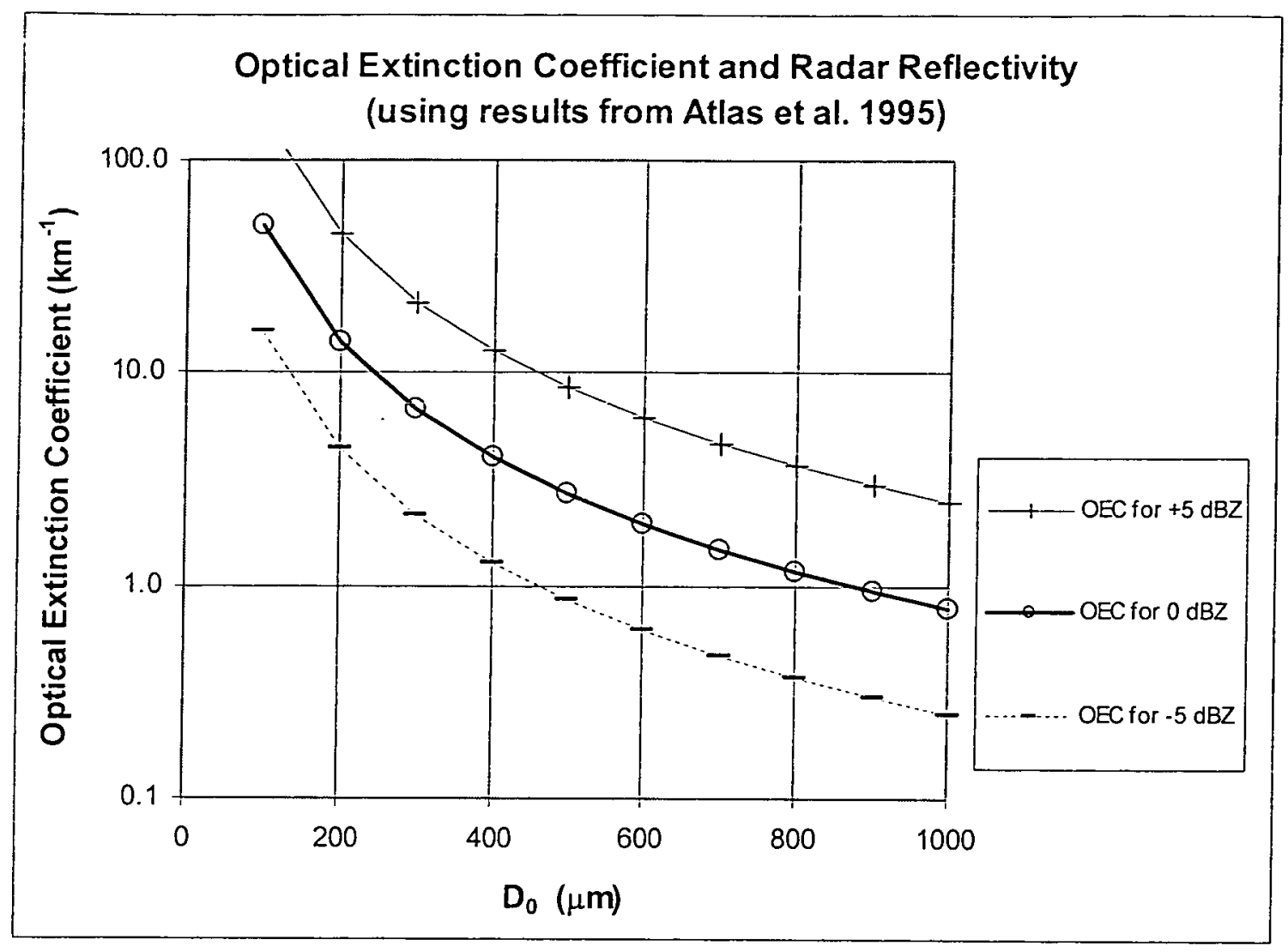

Figure 1. Optical extinction coefficient versus Do for $\mathrm{dBZ}$ values of $+5(+), 0(\mathrm{o})$ and $-5(-)$, computed from Equation 1.

Data from anvil clouds presented by McFarquhar and Heymsfield ${ }^{4}$ suggest $D_{0}$ values increasing downward from $100 \mu \mathrm{m}$ or less near cloud tops, to 300 to $500 \mu \mathrm{m}$ several $\mathrm{km}$ below the tops. Figure 1 indicates a $D_{0}$ value of $400 \mu \mathrm{m}$ would produce an optical extinction coefficient of $1.29 \mathrm{~km}^{-1}$ at $-5 \mathrm{dBZ}, 4.06 \mathrm{~km}^{-1}$ at $0 \mathrm{dBZ}$, and $12.85 \mathrm{~km}^{-1}$ at $+5 \mathrm{dBZ}$. A realistic geometric thickness of $2 \mathrm{~km}$ (9843 ft) would produce corresponding optical thicknesses as follows: 3.87 at $5 \mathrm{dBZ}, 12.18$ at $0 \mathrm{dBZ}$, and 38.55 at $+5 \mathrm{dBZ}$. The relation between optical thickness and transparency is explored next.

Determining the threshold of optical thickness that precisely separates transparent from nontransparent is beyond the scope of this study. Nevertheless, a useful optical thickness threshold can be obtained by considering an idealized optical medium and highly idealized viewing conditions. 
For a medium that scatters and absorbs visible radiation, such as haze or fog, an optical thickness of 3.912 is considered sufficient to obscure an object from the view of a typical human observer. ${ }^{5}$ This assumes that the limiting value of contrast for the human eye is $+/-0.02$, where the contrast between the brightness of an object $(B)$ and its background $\left(B_{0}\right)$ is defined as $\left(B-B_{0}\right) / B_{0}$. The optical thickness is the product of the OEC of the medium and the observer's distance from the object (the visual range), consistent with the discussion of Fig. 1 above.

\section{Observed Reflectivity and Cloud Boundaries}

In 2000 and 2001, an extensive field program was undertaken to determine the relationship between in-cloud electric fields and other cloud properties including radar reflectivity in order to improve the LLCC. This Airborne Field Mill (ABFM) program flew an aircraft carrying six electric field mills and a full suite of cloud physics instrumentation into central Florida thunderstorm anvil clouds during the summer convective season. ${ }^{6}$ Details of the aircraft and its instrumentation are found in Dye et al. ${ }^{7}$ All flights took place in the field of view of two weather radars: the Air Force WSR-74C $5 \mathrm{~cm}$ system at Patrick AFB, FL and the National Weather Service WSR-88D $10 \mathrm{~cm}$ Doppler system in Melbourne, FL. The aircraft and radar data were carefully synchronized in both time and space before analysis. All measurements were subject to the intensive calibration and quality control procedures described in Dye et al. ${ }^{7}$ The radar data are estimated to be accurate to within about $+1=1 \mathrm{dBZ}$. For a detailed discussion of $Z$ and its relation to cloud properties, see Doviak and Zrnic. ${ }^{8}$

Using an automated cloud edge detection algorithm based primarily on the airborne cloud

physics data, ${ }^{9}$ the radar reflectivity measured by the ground based radars was measured as a function of distance from cloud edge. The results are shown in Figure 2 based on data from both the WSR 74C and WSR 88D with redundant data eliminated. 


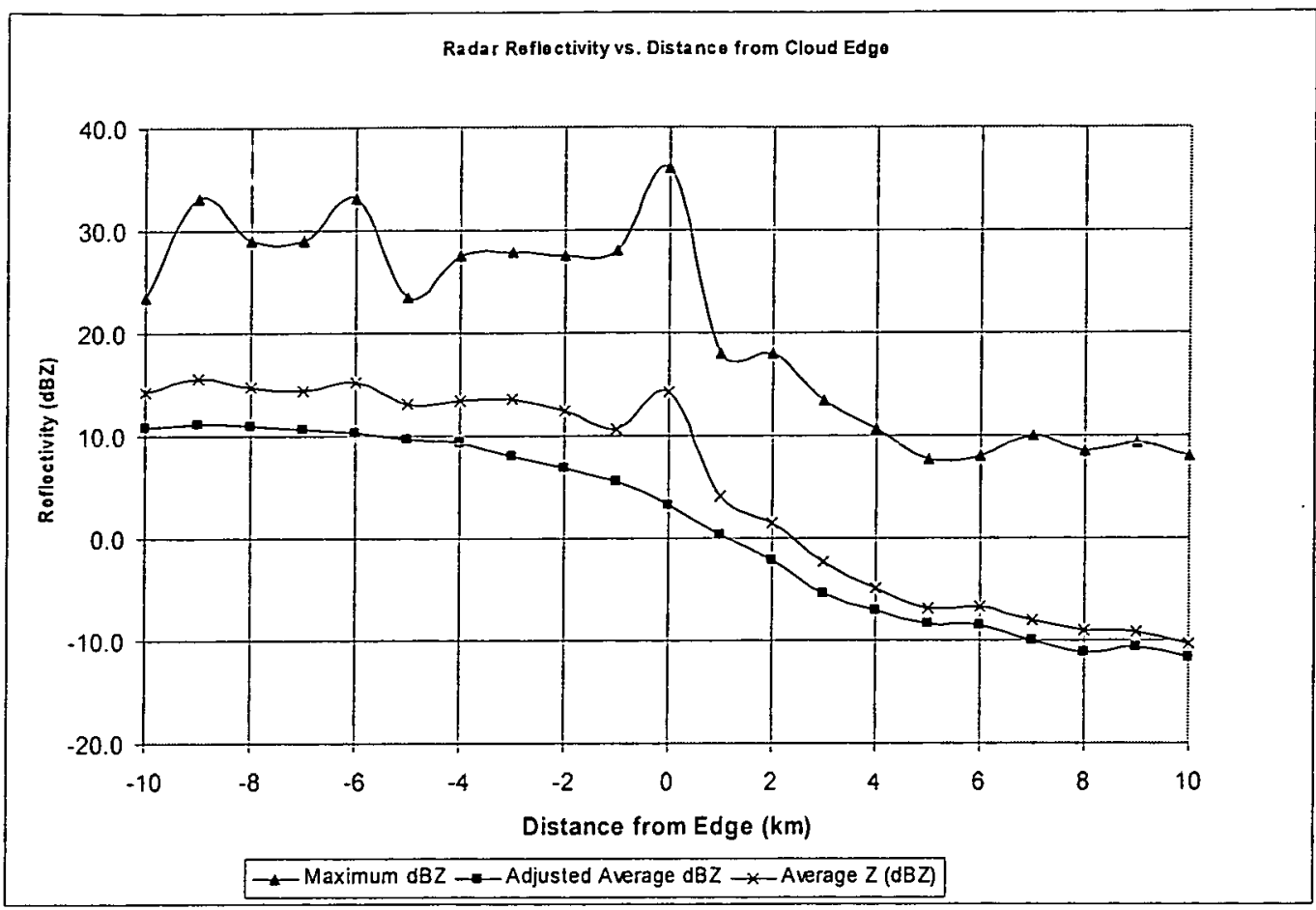

Figure 2. Maximum and average radar reflectivity $(\mathrm{dBZ})$ as a function of distance $(\mathrm{km})$ from the edges of anvil clouds. Positive distances are in clear air, and negative distances in cloud.

The average reflectivity was calculated in two ways denoted in the figure as "Average $Z$ (dBZ)" and "Adjusted Average dBZ". The first method converted the $\mathrm{dBZ}$ values reported by the radar to the equivalent values of $Z$ and averaged them. The result was converted back to $d B Z$. This methodology is quite sensitive to large outliers, which is why the shape of this curve in Figure 2 tends to track the shape of the maximum reflectivity curve.

The second method averaged the $\mathrm{dBZ}$ values reported by the radar. This produces a more representative average in the interior of clouds because it is less affected by a few large outliers, but it has a major weakness for our application. When the reflected signal drops below the noise floor of the radar, the radar reports "no signal". When averaging $\mathrm{Z}$ as in the first method, $\mathrm{Z}$ can be replaced with the value 0 with little error. When averaging $d B Z$, there is no equivalent finite value to insert for $\mathrm{dBZ}$ when the data are missing. In this case the average was corrected by adjusting the average for the missing clear air data as follows:

Adjusted Average $d B Z=$ Average $d B Z+10 \log _{10} R_{p}$ 
where $R_{p}=$ active pixels/total pixels.

The Figure shows that the two methods give essentially equivalent results. In both cases, the sampling error ranges from less than one $\mathrm{dBZ}$ in cloud to a maximum of $2.4 \mathrm{dBZ}$ in clear air. In clear air the two methods are within the sampling error. In cloud, the Average $\mathrm{Z}$ is slightly higher because of its sensitivity to peak values, but the difference is not significant to this discussion. Both methods yield average reflectivity that drops from $10 \mathrm{dBZ}$ or more in cloud to less than $-5 \mathrm{dBZ}$ outside of cloud. The transition takes place within $4 \mathrm{~km}$ of the cloud boundary.

\section{Observed Reflectivity and Transparency}

In the summer of 2003 an observational campaign was conducted at Kennedy Space Center to explore the relation between the transparency of anvil clouds, as determined by ground based observers at the Shuttle Landing Facility (identifier KTTS), and a standard radar reflectivity product from the National Weather Service radar (WSR-88D) in Melbourne, FL. The observers subjectively determined the transparency of high cirriform clouds overhead and recorded them as transparent when higher clouds, blue sky, the sun's disk, etc. could be distinctly seen or if the sun cast distinct shadows of objects on the ground. These guidelines are consistent with those used during space launch and landing operations by pilots of reconnaissance aircraft to determine the transparency of anvil clouds. Satellite imagery was analyzed afterward to determine if the clouds were anvil clouds originating from thunderstorm activity. Data for 45 days with anvil clouds was obtained during the months of June, July and August.

The WSR-88D Layer Reflectivity Maximum (LRM) product displays the maximum radar reflectivity $(\mathrm{dBZ})$ detected within a discrete vertical layer over each defined grid cell. It has been used to provide a quick assessment of the potential severity of thunderstorms. ${ }^{10}$ The grid cells have horizontal dimensions of $2.2 \times 2.2 \mathrm{n}$ mi. The LRM product is available for two layers that encompass the altitude range where anvil clouds are typically observed over Florida: Mid (24 000 to $33000 \mathrm{ft}$ ) and High (33000 to $60000 \mathrm{ft}$ ). The product is color coded into 7 categories, with the lowest category being $0-4 \mathrm{dBZ}$ and the next highest category being $5-18 \mathrm{dBZ}$. 
LRM Mid and High products from the Melbourne WSR-88D were obtained for our 45 case days from the National Climatic Data Center (NCDC). Of the 45 days, 41 had LRM products available and on those 41 days a total of 313 daylight hourly observations of thunderstorm anvil clouds were found with coincident LRM products and anvil transparency remarks from the KTTS observers.

A $3 \times 3$ grid of LRM cells was analyzed over the KTTS area to match the effective area monitored by the ground-based observers and to take into account navigation errors in the radar product due to daily variations in the refractive properties of the atmosphere. For each hourly KTTS observation with transparency remarks, the 9 values of each LRM product within the $3 \times 3$ grid were recorded as integers, 0 for $<0 \mathrm{dBZ}, 1$ for $\geq 0 \mathrm{dBZ}$. The record of anvil transparency remarks was merged with the integer values for the LRM Mid and High products and classified as follows for a categorical analysis: The observer evaluation was classified as "yes" for opaque anvil clouds and "no" for transparent anvil clouds. The radar indication was classified as "yes" if any of the 9 cells for either product had a value $>0$ and "no" if all of the 9 cells for both products had a value $=0$

Table 1 shows a standard contingency table used for computing verification statistics of the "observer evaluation" and "radar indication" of anvil transparency. The categorical data was entered in the $2 \times 2$ table of counts of the four possible combinations of yes/yes, yes/no, no/yes, and no/no.

Table 1. Contingency table of anvil transparency based on the KTTS observer's remarks and a combination of the LRM High or Mid radar product indication.

\begin{tabular}{|l|l|l|l|l|l|}
\hline \hline \multicolumn{2}{|c|}{} & \multicolumn{2}{|l|}{ Observer Evaluation } & & FAR $=10.1 \%$ \\
\cline { 2 - 6 } \multicolumn{2}{c|}{} & Yes & No & Total & PODy $=49.7 \%$ \\
\hline \multirow{3}{*}{$\begin{array}{l}\text { Radar } \\
\text { Indication }\end{array}$} & Yes & 80 & 9 & 89 & CSI $=0.471$ \\
\cline { 2 - 6 } & No & 81 & 143 & 224 & TSS $=0.532$ \\
\cline { 2 - 6 } & Total & 161 & 152 & 313 & HSS $=0.437$ \\
\hline
\end{tabular}

Table 1 shows 5 measures of performance as follows: 
- False Alarm Rate (FAR) of $10.1 \%$ shows that an LRM indication of anvil cloud has a high probability of being non-transparent.

- Probability of Detection of yes (PODy) of $49.7 \%$ shows that only about half the anvil clouds classified as opaque by the observer were detected in the radar product.

- Critical Success Index (CSI) of 0.471 gives the proportion of yes/yes events to the sum of yes/yes, yes/no, and no/yes.

- True Skill Statistic (TSS) of 0.532 provides a measure of the radar's ability to discriminate between transparent and non-transparent observations. A TSS of 0 would result if the radar indications were random ${ }^{11}$.

- Heidke Skill Score (HSS) of 0.437 gives the fraction of radar observations that were correct, adjusted for the number expected to be correct by chance.

Table 1 reflects a total of 313 evaluation/indication pairs corresponding to the hourly observations on 41 case days. The CSI, TSS and HSS indicate that the LRM provides a modest degree of skill in detecting non-transparent anvil clouds.

Reasons for the discrepancy between the observer's assessment of cloud transparency and the LRM product appear to be in the nature of the LRM product. It provides the maximum radar reflectivity detected throughout the depth of a pre-defined layer but provides no information on the geometric thickness of cloud within the layer and it has a lower cut-off at $0 \mathrm{dBZ}$. The lower cutoff and geometric thickness are important variables because theoretical calculations show that a cloud with a radar reflectivity below the cut-off $(<0 \mathrm{dBZ})$ could appear non-transparent to an observer if the cloud was sufficiently thick. An additional important variable is the size of the ice crystals composing the cloud. Small crystals tend to produce weaker radar echoes, but are highly effective in obstructing visibility. Large ice crystals produce stronger radar echoes, but are less effective than small crystals in obstructing visibility. 


\section{Discussion}

Since the original publication of Krider et al. ${ }^{2}$, the definition of the radar cloud edge in the LLCC has been changed from $10 \mathrm{dBZ}$ to $0 \mathrm{dBZ}$. The observed average radar reflectivity $(\mathrm{dBZ})$ at cloud edge was between 0 and $5 \mathrm{dBZ}$. This suggests that the recent revision of the limit specified in the LLCC was appropriate. The previous $10 \mathrm{dBZ}$ limit meant that the radar boundary was actually about $5 \mathrm{~km}$ inside the cloud on the average, a potentially unsafe condition. The 0 dBZ limit places the average boundary a kilometer or two outside the cloud whichever averaging method is used, a safe but not overly conservative distance.

The analysis of ground-based observer assessments of cloud transparency and the LRM radar reflectivity product support the notion that anvil clouds with radar reflectivity values as low as $0 \mathrm{dBZ}$ are likely to be non-transparent. These empirical results are consistent with theoretical calculations of radar reflectivity, optical extinction coefficient, cloud geometric thickness and optical thickness.

The observational data are consistent with the theory and each other, lending confidence in the use of radar for determining cloud boundaries and transparency when visual observations cannot be made.

\section{Acknowledgments}

The authors thank Computer Sciences Raytheon for providing the visual observations of cloud transparency and Drs. James Dye and Sharon Lewis for providing the archived ABFM data.

\section{References}

'W.W. Vaughan and S.C. Brown, 'Natural environmental considerations for Space Shuttle system development support," J. Spacecraft Rockets, Vol. 22, No. 3, 1985, pp. 355-360.

${ }^{2}$ E. P. Krider, H.C. Koons, R.L. Walterscheid, W.D. Rust, and J.C. Willett, "Natural and Triggered Lightning Launch Commit Criteria (LCC)," The Aerospace Co., TR-99(1413)-1, El Segundo, CA, 1999. 
${ }^{3}$ D. Atlas, S. Y. Matrosov, A. J. Heymsfield, M. D. Chou, and D. B. Wolff, "Radar and radiation properties of ice clouds" J. Appl. Meteor., Vol. 34, 1995, pp. 2329-2345.

${ }^{4}$ G. M. McFarquhar, and A. J. Heymsfield, "Microphysical characteristics of three anvils sampled during the Central Equatorial Pacific Experiment," J. Atmos. Sci., Vol. 53, 1996, pp. 2401-2423.

${ }^{5}$ R. G. Fleagle, and J. A. Businger, "An Introduction to Atmospheric Physics," International Geophysics Series, Vol. 5, Academic Press, New York, 1963, 346 pp.

${ }^{6}$ F.J. Merceret and H. Christian, "A Field Program to Facilitate Safe Relaxation of the Lightning Launch Commit Criteria for the American Space Program," Ninth AMS Conf. on Aviation and Range Meteorology, 6.4, Amer. Meteor. Soc., Orlando, FL, 2000, pp. 447-449.

${ }^{7}$ J.E. Dye, S. Lewis, M.G. Bateman, D.M. Mach, F.J. Merceret, J.G. Ward, and C.A. Grainger, "Final Report on the Airborne Field Mill Project (ABFM) 2000-2001 Field Campaign," NASA, NASA/TM-2004-211534, NASA Center for AeroSpace Information (CASI), 7121 Standard Drive, Hanover, MD 21076-1320, 2004.

${ }^{8}$ R.J. Doviak and D.S. Zrnic, Doppler Radar and Weather Observations, $2^{\text {nd }}$ ed., Academic Press, San Diego, CA, 1993.

${ }^{9}$ J.G Ward and F.J. Merceret, "An Automated Cloud-Edge Detection Algorithm Using Cloud Physics and Radar Data," J. Atmos. Oceanic Technol., Vol. 21, 2004, pp. 762-765.

${ }^{10} \mathrm{R}$. J. Turner, "The operational use of the WSR-88D Mid- and High-level layer composite reflectivity products to assess the severe weather potential of thunderstorms," Preprints of the $14^{\text {th }}$ Conference on Weather Analysis and Forecasting, January 15-20, Dallas, 1995, pp. 459-464.

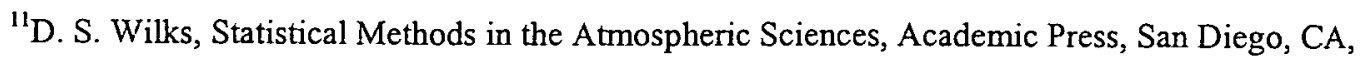
$1995,467 \mathrm{pp}$. 